\section{Journals as policemen}

Up to a point, the US Congress may be able to enlist the help of journals in cleaning up the record of research.

SomE wag in the US Congress has hit on a novel way of regulating the conduct of the scientific journals: let them toe the line, or their contents will be indexed separately or not at all by the National Library of Medicine and thus not retrievable through the many databases the library compiles and maintains. The tortuous origins of this proposal are described on page 7 of this issue. The question of why there should be a line is simply answered; to eliminate fraudulent and otherwise suspect findings from the scientific record. But where the line is to be drawn is not answered by the bill, but will be decided by consultation between the National Institutes of Health's Office of Scientific Integrity (OSI) and the editors of journals.

At least for journals strong in modern biology, and especially for their contributors, the proposed sanction will be a powerful influence towards compliance. Among other things, the sponsors of the legislation apparently have it in mind that journals should be prepared to publish retractions of invalid research reports in a form that will ensure that the retraction is eventually mated bibliographically with the original. Thus stated, the plan is unexceptionable. Many journals (Nature included) follow such a course already. Others, mystifyingly, refuse to do so on the grounds that their standing might then be compromised. A little coercion would help mightily.

But what exactly is a retraction? First, even when made explicit, it is not necessarily a confession of dishonesty on anybody's part. Honest mistakes happen, as with last year's misinterpretation of pulsar data suggesting that there is a planet around a particular neutron star, and are as often as not retracted quickly and honestly. Will the US Congress allow that retractions, always painful for the authors, are not always marks of venality? And what is to be made of retractions that masquerade as reports of further and apparently successful research, as when an author reports results whose effect is to restrict the generality of a phenomenon previously reported? Or when an author follows a report in one journal with a report in a second journal that evidently supersedes the first? Such practices are probably more common than supposed, but journals cannot police them. Nor can journals confidently arbitrate in cases where, after publication, authors disagree about the validity of what they have published. (They can, of course, and should, report the disagreement.)

There are more serious dangers in what the Congress is brooding about. Few serious journals would cavil at the enforcement of a common policy on the form of retractions, but there would be much more serious doubts over policies to apportion credit for research results among the several authors of a joint research report or to compel the sharing of research materials with all enquirers (desirable though that may be). Journals with academic pretensions, knowing their contributors to be mostly honest and meticulous, but knowing little of what Congress is up to, will be naturally less distrustful of the former than the latter. That is why close attention will be paid to OSI's negotiations with journals if this legislation becomes US law.

\section{Britain's new chance}

The British government should not waste the opportunity it has given itself of restoring battered relations.

Is the British government, still glowing warmly after its unexpected election victory this month, able to seize the opportunity it has given itself to put British science in better shape? The decision to give a minister (Mr William Waldegrave) part-time responsibility for science is welcome in itself, but is also an opportunity for a fresh start. For far too long, the government's rejoinder to complaints at its handling of British science has been complacent denial. With a new organization, it can begin to make more intelligent responses.

On the administrative side, there is a difficult trick to perform. The designation of a minister with responsibility for science is the biggest organizational change since 1971, but the British scientific community is fed up to the teeth with reorganization, and needs a respite from it. How to marry these circumstances? By leaving the supposedly autonomous research councils, the chief sources of funds for academically related research, intact for the time being. Indeed, they all deserve a greater sense of responsibility within their terms of reference.

That argues for letting lapse the Advisory Board for the Research Councils (ABRC), whose chief function is to divide the annual budget for civil science between the research councils and the Royal Society, when its now fulltime chairman, Sir David Phillips, retires next year. (Technically, ABRC gives advice only, but only contentious ministers such as Sir Keith Joseph reject it.) The truth is that $\mathrm{ABRC}$ has become a needless irritant to its dependants, more a part of the problem than of its solution. The research councils would probably be better off arguing their case with civil servants direct.

There is also a case for letting lapse the government's other chief advisory committee in the field, the Advisory Council on Science and Technology (ACOST), intended as a means of carrying out perceptive studies of important issues, but which has consistently failed to achieve its mission (perhaps for lack of adequate resources). This journal (see Nature 356, 644; 1992) would rather have an independent committee to act as a lightning rod and sounding-board for the opinions of the scientific community (malcontent and otherwise) and with the freedom to publish its reflections on them. But there is no great hurry. If this is to be a new beginning, it is better that the government should spend time building an organization that will last than that it should settle for another Kleenex institution, one destined to be discarded soon. 